\title{
Videoclip musical y creatividad audiovisual: un análisis del canal Music Video Land de Vimeo
}

\author{
Ana Sedeño-Valdellós \\ Universidad de Málaga (España). \\ valdellos@uma.es \\ Fecha de finalización: 31 de marzo 2020 \\ Recibido: 31 de marzo de 2020 \\ Aceptado: 7 de septiembre de 2020. \\ DOI: https://doi.org/10.26422/aucom.2020.0902.sed
}

\section{Resumen}

El videoclip musical supone un formato de referencia en el audiovisual contemporáneo, ya sea por sus estrategias transmedia, por la variedad de las interrelaciones entre videoclip original $\mathrm{u}$ oficial y sus híbridos procedentes de la comunidad fan o por los remakes o videos derivados. Las plataformas de vídeo se han convertido en la forma central en la que se consumen y comparten contenidos visuales para la música popular y una principal fuente de negocio empresarial; entre ellas, YouTube es la más conocida y estudiada. El trabajo presenta un análisis del videoclip musical con más me gusta en el canal Music Video Land de Vimeo, comisariado por autores de IMVdb (The Internet Music Video Database), principal plataforma especializada de archivo y comisariado de videos musicales de internet. Se aplica un análisis cuantitativo que combina los criterios clásicos -tipo de videoclip, tipo de relación música/imagen, tipo de relación imagen/ texto y género musical- junto a un estudio de las técnicas específicas de realización y de animación. Se concluye que el videoclip conceptual de música dance/electrónica e indie, con una importante presencia de técnicas avanzadas de realización y composición de imagen, resulta el más elegido por los comisarios y usuarios del canal.

Palabras clave: videoclip musical, Vimeo, plataformas audiovisuales, creatividad audioviosual, YouTube.

\section{Music videos and audiovisual creativity: an analysis of the Music Video Land channel on Vimeo}

\begin{abstract}
Music videos are reference points in the current audiovisual landscape. This is due to the transmedia strategies they employ, the interrelations between official music videos and their adaptations by the fan community, and the remakes and remixes they leave in their wake. Today, most music videos are consumed and shared via online video platforms, which have become a vital source of
\end{abstract}


income for the music business. Of these platforms, YouTube is the most well-known and studied. However, in this paper, we will analyze the music video with the greatest number of "likes" in the Music Video Land channel on Vimeo. The contents of this channel are curated by the authors of the IMVdb (Internet Music Video Database), the most important music video archive and repository of information on the web. We will carry out a quantitative analysis, combining classic criteria - such as genre, type of music video, relationship between music and image or between image and text - with a look at specific animation and filming techniques. We conclude that concept music videos for dance/electronica or indie tracks, made with advanced filming and image composition techniques, are the most popular among the curators and users of this channel.

Keywords: music video, Vimeo, audiovisual platforms, audiovisual creativity, YouTube.

\section{Videoclipe musical e criatividade audiovisual: uma análise do canal Music Video Land em Vimeo}

\section{Resumo}

O videoclipe musical oferece um formato de referência no audiovisual contemporâneo, seja por suas estratégias transmediárias, pela variedade das inter-relações entre um videoclipe original ou oficial e seus hibridos derivados da comunidade de fãs ou o pelos remakes ou vídeos derivados. As plataformas de vídeo se tornaram a forma central pela qual o conteúdo visual é consumido e compartilhado para a música popular e uma fonte principal de negócios; Dentre eles, o YouTube é o mais conhecido e estudado. $O$ trabalho apresenta uma análise do videoclipe mais curtido no canal Music Video Land do Vimeo, com curadoria de autores do IMVdb (The Internet Music Video Database), principal plataforma especializada para arquivamento e curadoria de videoclipes na internet. É aplicada uma análise quantitativa que combina os critérios clássicos - tipo de videoclipe, tipo de relação música / imagem, tipo de relação imagem / texto e gênero musical - juntamente com um estudo das técnicas específicas de produção e animação. Conclui-se que o videoclipe conceitual de música dance / eletrônica e indie, com presença significativa de técnicas avançadas de produção e composição de imagens, é o mais escolhido pelos curadores e usuários do canal.

Palavras chave: videoclipe musical, Vimeo, plataformas audiovisuais, creatividade audiovisual, YouTube.

\section{Introducción: la diversidad del formato videoclip en la cultura digital}

En esta ecología contemporánea en la que las imágenes son inabordables en su complejidad, hibridación y mutación constante, los estudios visuales, los de la performance, los digitales, la analítica cultural y otros muchos planteamientos tratan de dar cuenta de la extrema variedad de las imágenes y de las prácticas de su circulación, producción y consumo.

Sin embargo, algunas de sus concreciones en formatos se resisten al análisis. Un vídeo musical es un formato de producción audiovisual que supone un conjunto de discursos, un sistema de códigos visuales de sentido e interrelaciones que pueden analizarse desde varios puntos de vista. Mueve más de 3443 millones de euros de recursos económicos, un 33\% del total del contenido audiovisual actual, y es un contenido prin- 
cipal en internet; su inclusión en la plataforma YouTube y en otras redes sociales les proporciona una distribución impensable a los contenidos audiovisuales en la cultura contemporánea y abre gran cantidad de cuestiones sobre el alcance, uso y vida útil de los discursos visuales.

Los videoclips se enmarcan plenamente en la concepción "espectáculo-mercancía" dominante en la sociedad contemporánea. Son portadores de mensajes y valores que van más allá de un contenido literal, los cuales conducen a la creación de sentido simbólico junto a elementos como la portada del disco, la puesta en escena del concierto, entrevistas, todo ello a lo largo de carreras de décadas en un bucle continuo de retroalimentación. Existen otros factores de definición del "texto-estrella", como los provenientes de los géneros musicales y sus universos de puesta en escena: el rap, el rock, el heavy, todos los géneros musicales básicos de la música popular buscan una puesta en escena básica y tienden a consolidarla a través de los diferentes "textos" con los que se presentan a sus seguidores. La producción con herramientas digitales y distribución en la red a través de plataformas exclusivas de vídeo permiten la multiplicidad de posibilidades en la fase de consumo y exhibición de los vídeos en los distintos canales/ ventanas en la red: también plataformas como Spotify o Shazam tienen opciones para visualizar y relacionarse con ellos. Por un lado, las herramientas digitales han supuesto un cambio en las modalidades de producción audiovisual y en sus características (abaratamiento, versatilidad) y en las de edición (posproducción del mensaje, técnicas de animación, diseño e imagen generativa, etcétera).

Pero no terminan aquí los procesos por los que el videoclip se transforma y se introduce en la lógica global. Las estrategias transmedia suponen un contexto de investigación y creación en expansión en el campo de la comunicación actual. Su propósito de servir al surgimiento de novedosos proyectos culturales -especialmente planificados- en los que se construye un mundo narrativo multiplataforma en permanente expansión o potencialmente desarrollable permite fundar un contexto diseñado de singularidad a través de fórmulas de engagement y capas creativas de contenido con las que seducir el espectador y atraerlo hacia una propuesta cultural, comunicativa y artística única.

El videoclip contemporáneo, coherente con las peculiaridades de un nuevo ecosistema (Scolari, 2013), se ha basado en esa necesidad de la industria del entretenimiento, de la industria musical, de integrar sus productos en un contexto multimediático. Carol Vernallis (2013) menciona que existe una segunda etapa de la estética videoclip, en la que su narrativa y discurso se han visto modificados por la incorporación de macrosites (Vimeo, YouTube), la irrupción del fan video -más tarde, derivative video- y la llegada del videoclip interactivo, el vídeo musical móvil, el web-based o el videoclip transmedia. Esto está modificando la manera de entender el formato y su ubicación en 
Ana Sedeño-Valdellós

Videoclip musical y creatividad audiovisual: un análisis del canal Music Video Land de Vimeo

el espectro de géneros audiovisuales. El videoclip está adaptándose tan certeramente a las nuevas narrativas digitales e interactivas que puede hablarse de una nueva era del videoclip, que podríamos llamar "postelevisiva” (Sedeño-Valdellós, Rodríguez-López y Roger-Acuña, 2016).

Hemos compartido con Carol Vernallis (2013) la necesidad de analizar el videoclip en esta segunda etapa de su estética, apuntando que la incorporación de macrosites, la irrupción del fan video o music user s video y la interactividad han modificado los perfiles de su producción y recepción, pero sobre todo han abierto muchos más canales para su distribución, limitada anteriormente al régimen televisivo. La autora norteamericana, en su trabajo Music video seconds aesthetics, en Unruly Media: YouTube, music video and the new digital cinema (2013), describe un panorama genérico del videoclip en esta segunda gran etapa y destaca la imposibilidad de establecer un dibujo certero de la identidad videoclipera.

\begin{abstract}
YouTube dificulta especialmente trazar una línea divisoria entre lo que es un vídeo musical y lo que no. Podríamos mantener todos los atributos que alguna vez formaron un vídeo musical flotando como una constelación en la sombra, pidiéndoles que nos ayuden a leer los nuevos clips. También podríamos fortalecer la definición para incluir el requisito de que las imágenes parezcan dedicadas a mostrar a la banda sonora hasta cierto punto, pero incluso agregar este corolario proporciona poca asistencia. La música, el sonido y la imagen pueden estar tan estrechamente entrelazados en algunos segmentos en el cine contemporáneo que podríamos verlos como secuencias de vídeos musicales: una vez que aparecen en YouTube, pueden parecer indistinguibles de otros clips. También en grandes segmentos de las películas de hoy, la banda sonora puede ser más llamativa que la imagen. Por el contrario, en YouTube, algunos vídeos musicales tienen una banda sonora tan pasiva que casi no hay nada que mostrar, pero estos clips no son más que vídeos musicales (Vernallis, 2013, pp. 208-209). ${ }^{1}$
\end{abstract}

A pesar de esta impotencia ocasional o estratégica, Vernallis (2013) realiza el más amplio análisis comparativo entre los videoclips de la década del 80 y los actuales. Describe los cambios en rasgos como el color, la materialidad y los microrritmos musicales, la realización y la edición, la narrativa y la estructura del vídeo, el tipo de performance, la intertextualidad y las posibilidades de remediación de material. La autora describe esta segunda etapa como un videoclip con las siguientes características:

- Pulso, reiteración y otras formas de musicalidad.

- Irrealidad e ingravidez.

- Escala y valores gráficos.

- Relaciones causales inusuales.

- Variabilidad e intertextualidad.

- Humor y parodia.

- Volubilidad y otra condensación.

Traducción propia. 
Además, los usuarios producen todo tipo de contenidos al margen de las industrias culturales, lo que permite una hibridación y versatilidad de géneros y formatos que no siempre es posible diferenciar. Korsgaard $(2013 ; 2018)$ también describe un videoclip musical transformado - una segunda época de oro-, dominado por el fan video, representativo desde los inicios de internet de cómo el fan se adueña del medio de expresión, de su capacidad para obtener conocimientos técnicos considerados especializados y de cómo se adaptan tecnologías existentes y habilidades para promover comunidades digitales de seguidores (Karpovich, 2009; Sedeño-Valdellós, 2012). Peverini (2010) está de acuerdo en que la estética del vídeo es un debate abierto hoy más que nunca y ello "implica no sólo la innovación tecnológica y el paisaje digital, sino también dinámicas más profundas, donde el cuerpo del artista y la mirada del espectador/lector chocan" (Peverini, 2010, p. 150).

Aunque compartimos esta idea de dificultad de su descripción o dibujo en un trazo, creemos que quizás su heterogeneidad motiva esa sensación intuitiva analítica de académicos (y de receptores) de que "todo puede ser un videoclip", que puede haber videoclips de todo tipo, que no existe algo así como un género o formato específico. Sin embargo, creemos que en la era de las redes sociales y de los contenidos digitales, plurales y distribuidos de múltiples formas, se vuelve prioritario realizar un análisis especializado del videoclip. Creemos que el tipo de consumidor o receptor podría condicionar el perfil de los vídeos escogidos y subidos por las plataformas.

Internet es el mayor distribuidor de vídeos musicales (Picazo-Sánchez, 2016). El vídeo ha pasado de su centralización en la programación de dos o tres canales televisivos a estar disperso por internet (Austerlitz, 2007). Sitios como YouTube, Myspace -en su momento- $y$ ahora Vimeo o incluso Tik Tok recogen toda la producción oficial y de sus seguidores y forman perfiles de videos y de usuario. Por su parte, Arroyo Almaraz y Baños (2013) afirman que

\begin{abstract}
los medios sociales, cada vez más, se apoyan en la presencia del vídeo viral para ser compartido y comentado en las redes sociales y, en este sentido, YouTube cumple una labor fundamental como distribuidor de esos vídeos, desde donde serán dados a conocer a través de las redes sociales: Facebook, Twitter, Tuenti, etc. (Arroyo Almaraz y Baños, 2013, p. 616).
\end{abstract}

Aunque YouTube es la principal plataforma desde la cual se puede acceder a contenidos visuales -especialmente de videoclip-, otros -como Vimeo- se posicionan como selectos ejemplos de creatividad audiovisual y son empleados por creadores audiovisuales (directores, productores) para mostrar y compartir sus creaciones; además, en sus opciones premium ofrece enviar los trabajos para su asesoramiento y modificación colaborativa a través de equipos dispersos por todo el mundo. 
Ana Sedeño-Valdellós

Videoclip musical y creatividad audiovisual: un análisis del canal Music Video Land de Vimeo

La capacidad viral de YouTube como plataforma ha animado a millones de prosumidores a subir contenidos, dada la combinación de la popularidad de quien comparte y de sus productores, las tendencias sociales del momento y la calidad intrínseca del vídeo (Sachak-Patwa, Fadai y Van Gorder, 2018). Creemos que, al contrario de lo que ha ocurrido con YouTube -con estudios sobre la viralidad y el éxito de sus videos que nos hacen comprender las razones que explican la popularidad de los vídeos en línea de cara a la publicidad que se encuentra en los canales y otros contenidos (Kong, Rizoiu, Siqi y Xie, 2018)-, Vimeo adolece de estudios empíricos y análisis sobre un segundo universo del videoclip alejado del mainstream.

La descripción de esta segunda etapa del videoclip en el universo contemporáneo es coherente con un gusto especial por lo digital y por su efecto sobre la visualización del cuerpo transformado por la tecnología: Manovich (2013) ha descrito en Software takes command cómo el software ha compuesto unas formas culturales que suponen una transformación de la vida a través de su intermediación mediante interfaces. La performance musical contemporánea se construye por medio del laptop y no mediante una arquitectura de guion narrativo clásico: Berland (2008) introduce el término postmusics argumentando que la música digital ha provocado un descubrimiento del gesto físico del músico humano a partir de la noción de agencia sonora.

El formato ha mantenido una iconicidad fotográfica, aunque modificada por una multiplicidad de códigos connotativos y técnicas visuales de posproducción alejadas de una articulación narrativa clásica y más cercanas a la mutabilidad constante de los parámetros de la imagen: Vernallis (2004, p. 197) habla de una narratividad débil (slow disclosure) o progresión de tipo circular, más que lineal. Por el contrario, el videoclip despliega estrategias de seducción cada vez más sofisticadas. La sensorialidad de estos efectos se encuentra en el origen de una nueva sensibilidad audiovisual que comenzó en la década del 80 con la consolidación del formato, pero sigue manteniendo su nivel de experimentación de forma tal que inspira a la esfera audiovisual digital desde sus comienzos. Esta sensibilidad la ha descrito Steven Shaviro (2010) señalando que "las continuas metamorfosis de la sensación se adelantan, se deslizan y se deslizan debajo, y amenazan con desalojar todas las comodidades y estabilidades del significado" (p. 33). De igual manera apunta Korsgaard (2012):

\footnotetext{
Las continuas modulaciones audiovisuales del vídeo musical rara vez permiten la estabilidad de cualquier significado. En cada momento, algo cambia. La percepción sinestésica ofrecida en el vídeo musical parece reforzar aún más el potencial afectivo; el carácter sensual y multimodal del vídeo genera significados que son más directamente afectivos y menos directamente descifrables (Korsgaard, 2012, p. 7).
} 
Austral Comunicación

Volumen 9, número 2 (Diciembre de 2020): 275-298. ISSN 2313-9129

Inestabilidad del significado que conduce más que a un sentido de mímesis de la representación a uno de modificación perpetua de las condiciones espacio-temporales en nuestra época: el ser no es ya ser por existir, sino por mutar, por modificarse.

El vídeo musical utiliza estas condiciones como recurso de significado, por lo que opciones como el time remapping, la cámara lenta, la cámara atrás y sus innumerables combinaciones confeccionan una representación temporal múltiple, ajena a la cronología lineal que es especialmente presente en los videoclips no narrativos -conceptuales- y performance: "time remapping consiste en la ampliación y reasignación del tiempo para conseguir efectos de movimiento a cámara lenta y cámara rápida” (JódarMarín, 2017, p. 125).

\section{Vimeo y su canal Music Video Land: objetivos, muestra y metodología}

De esta manera, surge el acercamiento a una plataforma escasamente analizada de difusión de videoclips en esta segunda etapa postelevisiva. Vimeo es una de las plataformas de visualización de vídeos cortos o contenido audiovisual más importante del mundo, en la que más profesionales confían para subir sus vídeos con objetivo de visibilización, comercial o de almacenamiento. La plataforma es un intrincado conjunto de tipos de canales, categorías y subcategorías que incluye material de autor publicado, borradores de autores disponibles para clientes, showreels o material de portfolio. Posee calidad y rapidez en la subida de contenido y ofrece opciones de privacidad y posibilidad de crear grupos de visionado (compartir contenidos) para su revisión entre profesionales y empresarios del sector audiovisual.

Existen varios canales dentro de la categoría Música en la plataforma. Esta se subdivide en tres: Live Music, Music Documentary y Music Videos. En esta última subcategoría encontramos 14 canales: Music, Music Video Land, HD Music Videos, La Huche, Music Videos, Music Videos HD, La Blogothèque, Hip Hop Music Videos, \#FMFVideopicks, Vimeo User Music Videos, CHLLWV, Boogie Down, Röyksopp y Vimeo Festival Screening - Hangover (Figura 1).

Music Video Land es un canal de Vimeo en el que comisarios especialistas de Internet Music Database (imvdb.net) eligen, comentan y curan videoclips. Este canal se reconoce por su tono indie y de videoclip creativo que resulta una alternativa a los videoclips más visualizados en YouTube, pertenecientes a géneros como reggaeton, salsa, pop y otros tipos de música de las más vendidas.

Por lo tanto, dentro de ellos se encuentra un gran número de Staff Picks, descritos como "The best shorts films on the internet. Brand new videos, exclusively premiering on Vimeo and handpicked by our curation team". ${ }^{2}$ Como se describe en la plataforma,

2 https://vimeo.com/channels/staffpicks. 


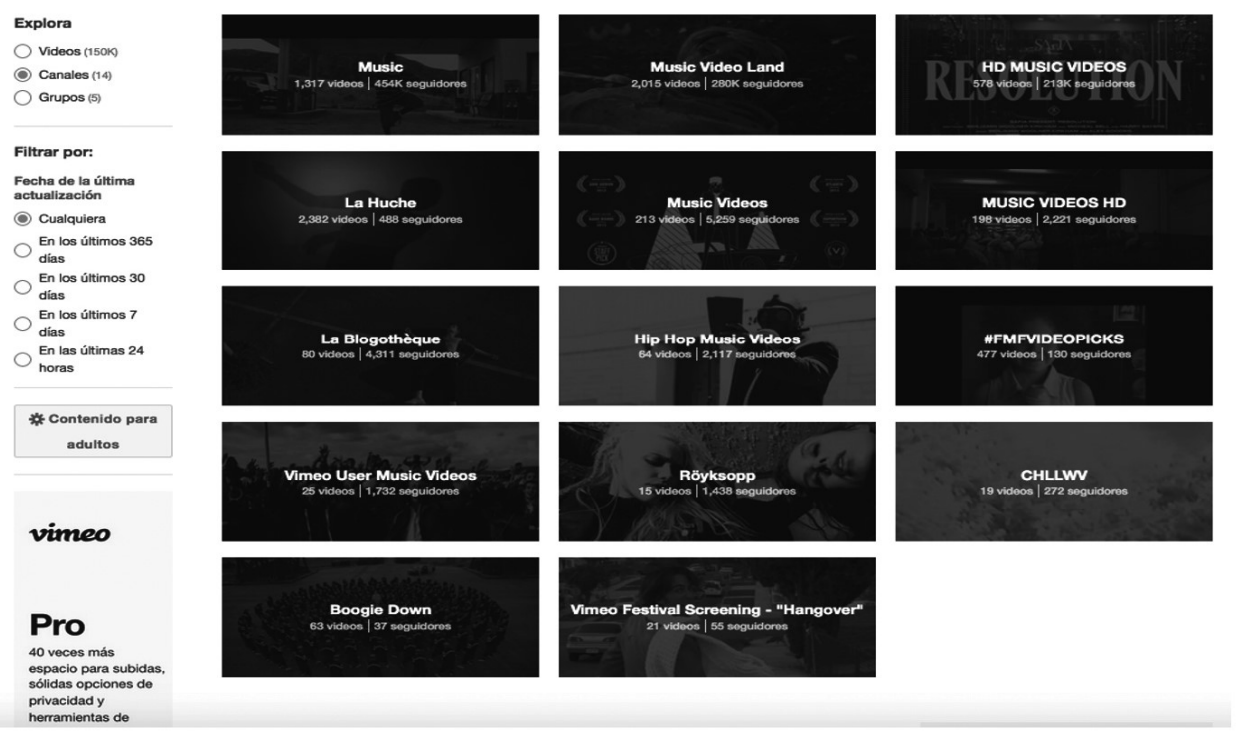

Figura 1. Canales de Vimeo sobre videoclip musical.

supone un reconocimiento que realizan los webmasters y que no tiene que ver con el proceder de Vimeo Premium, Vimeo Pro, Vimeo Bussiness o Vimeo Plus ni de ningún tipo de canal o tipo de suscripción; es una distinción sobre creaciones de especial calidad para los curadores.

Ante este planteo, y siguiendo algunos modelos de análisis (Sedeño-Valdellós, Rodríguez-López y Roger-Acuña, 2016; Vernallis, 2013), los objetivos generales de este trabajo son:

- Realizar una descripción y análisis de los videoclips del canal Music Video Land.

- Conocer los códigos de connotación básicos de estos vídeos en cuanto a tipo de animación, efectos visuales (VFX), relación música-imagen e imagen-texto.

- Describir un perfil del videoclip musical creativo o de autor de este canal de Vimeo.

Se asume que la aspiración específica de Music Video Land de ser un canal de videos musicales de alta creatividad debería significar que tiendan a ofrecer otros recursos visuales de los meramente narrativos, los que suponen un empleo de técnicas de posproducción y animación, configuraciones de la representación temporal y espacial no naturalistas y relaciones de sincronía (texto/imagen y texto/música) diversas. Conocer qué género musical se halla de manera mayoritaria permitirá establecer el 
perfil músico-visual del videoclip en Vimeo frente al videoclip mainstream de pop y rock que más se visualiza (y con más me gusta) en YouTube.

El universo de este estudio incluye todos los videoclips de este canal, que a fines de marzo de 2019 ascendían a 2063. De este total de casos, para el análisis como textos visuales por criterios que se detalla a continuación se han escogido los 150 con mayor número de me gusta en el canal, los cuales se listan en la Tabla $1 .{ }^{3}$ Ha sido necesario proceder a un depurado de la muestra, ya que algunos de los que aparecían no podían ser considerados como videoclips musicales, sino como cortometrajes o breves obras de videoarte, como Marbel Machine de Kindergarten.

\section{0 videoclips en Music Video Land}

- Bad Motherfuckers Biting Elbow (2013)

- Clichés Hierophante (2015)

- Not Butter Dillon Francis (2019)

- Luv Deluxe Cinnamon Chasers (2009)

- Everything you want Clubfeet (2013)

- You can? be my girl Darwin Deez -2013

- Ma'agalim Jane Bordeaux (2014)

- River Leon Bridge (2017)

- Kill the calories Vitalic-Stamina (2013)

- The Bay Metronomy (2011)

- Breezeblocks J+Alt S(A) (2012)

- ls tropical Lovers cave (2013)

- Katachi Shugo Tokumaru (2013)

- Tharsis Sleeps Throne (2014)

- The mess she nade Darwin Deez (2015)

- Magma The Vein (2012)

- Lips Human Human (2014)

- Crossing borders Booka shade (2013)

- Bad girls MIA (2010) L

- ife in gray Point Point (2015)

- Treat me right Keus n Dreater (2013)

- Gold Chet Faker (2014)

- The Hundred in the hands Pigeons (2010)

También pueden encontrarse por orden eligiendo la visualización/organización de los videos por me gusta en: https://vimeo.com/channels/musicvideoland/videos/sort:likes/format:thumbnail. 
- Paradise Awarts ZHU (2014)

- The less 1 know the better Tame Impela (2015)

- Ham Mr. Oizo (2014)

- Simple song The Shins (2007)

- Borra Free MIA (2010)

- Love Like Jack and the Giant (2014)

- Youth Ben Khan (2014)

- Ko/shick Leningrade (2017)

- Like it doesn't hurt Charlotte Cardin (feat. Husser) (2017)

- ChtIM Earl sweathirt (2012)

- Cirros Bonobo (2013)

- Tuna Melt A-Track \& Tommy Trash (2013)

- Somebody new Joywave (2014)

- Flames Johan Karl X (director cut) Toumiquet Hem (2013)

- Anthem Kawehi (2014)

- Unconditional rebel Siska (2015)

- Sct .ssors Liars (2010)

- Koudlan-Waiting for a sign Scratch massive (2011)

- Loud like love Placebo Feat. Bret Easton Ellis Shock Horror Shy Luv (2017)

- The drug Roysopp (2010)

- My recurring dream ColdMailman (2017)

- Riptide Vance Joy (2017)

- What if 1 go Mura Masa (2016)

- Sweater Willow (2012)

- The new international sound, Pt.2 GENER810n +MIA (2015)

- Bitten by The frost 0lly Knights (2012)

- Nobody speak DJ Shadow ft. Run the Jewels(2016)

- Animation Young Juvenile Youth (2016)

- Fantasía Fur voice (2015) lron Sky Paolo Nutini (2014)

- Dreams Husbands (2013)

- Digital Witness St. Vicent (2014)

- I will never change Benga (2013)

- Ride the Prejudice Phonat (2014)

- Coronus, the terminator" Flying Lotus (2014)

- Gosh Jamie XX (2015) I love it Postino (2014)

- Sweat Major Lazer (2013)

- Wide open The Chemical Brothers (2015)

- Shapeshifting Color War (2015) 
- Never say never Bassement Jaxx (2014)

- Set it off Diplo (feat. Lazerdisk Party sex) (2012)

- I love you so Cassius (2017)

- Round round song Adrian Sleber (2013)

- No reason Bonobo (2017)

- Hope Kid Wise (2015)

- Embers Woodkid-the golden age feat. Max Richters (2014)

- Trying to be cool Phoenix (2013)

- Everytime Oi Va Voi (2009)

- Stay awhile She \& Him (2014) Up \& Up Coldplay (2015)

- Deep down low Valentino Khan (2015)

- Afterlife Arcade fire (2013)

- Splitting the Atom Massive Attack (2010)

- Earth Dream Koala (2014)

- Will do Tv on the radio (2011)

- Mayo Kero Roy Kafri (2011)

- Back to me Joel Compass (2013)

- Dis generation A tribe called quest (2016)

- Defiant Order Birdy Nam Nam (2014)

- Hunger of the pire alt-j (2014)

- MERCY Kayne West ft. Big Sean, Pucha T, and 2 Chainz (2012)

- All your words JIL (2018)

- Not giving in Rudimental (2013)

- We the people Nike \& Chance the Rapper (2016)

- Witch Doctor De Staat (2013)

- Out of the black Royal Blood (2013)

- Ophelia The Lumineers (2016)

- She's bad Dye Feat. Egyptian Lover, (2014)

- Leave the world behind Lune (2014)

- Overgrow James Blake (2013)

- True Romance Citizens (2012)

- Eclipse Robot Koch (2015)

- Greatness Karma Fields feat. Talib Kweli Be around Peach King (2014)

- Montana Youth Lagoon (2011)

- M Swim good Frank Ocean (2011)

- King Grades (2015)

- Moments Teebs (2010)

- High Road Cufts (2013) 
- Sober Childish Gambino (2014)

- Sweatpants Childish Gambino (2014)

- Lone Digger Caravan Palace (2015)

- Can? you don't Charles X (2016)

- Phantasm Flying Lotus (feat Laura Darlington) (2012)

- Blackcar Leon Else (2016)

- Spitfire Porter Robingson (2011)

- Tongues Joywave (2015)

- Magnolia Lush life (2012)

- Beatsofreen Slowly rising (2015)

- Mr. Martyr Youngfathers (2013)

- Drinkee Sofi Tucker (2015)

- Nouveau perfum Boogie (2013)

- She knows J. Cole (feat. Amber Coffman, Cufts) (2014)

- Patience Damian Marley \&Nas (2010)

- Stress Justice (2010)

- Wyclef Jean Young Thug (2016)

- The Magician Andy Shauf (2016)

- Lenny Kravit Alexander Chatelard (2016)

- Wasting my young years London Grammar (2013)

- Genghis Khan Mike Sknow (2016)

- Never catch me Flying Lotus (feat. Kendrick Lamar) (2014)

- Manon De Jeugd van Tegenwoordig (2015)

- Marcus Marr Chet Faker (2015)

- Boys Latin Panda Bear (2015)

- Golde'? tree Martin Brrooks (2011)

- Postcards from 1952 Explosions in the sky (2011)

- Tum me out Russ Chimes (2013) LSD ASAP Rocky (2015)

- Don? sing Data (2015)

- Cry like a ghost Passion Pit (2012).

- CityScape Mike Luck (2013)

- Remember Raveyards (2012)

- Nie muszq wracae Pezet x Jimet (2012)

- Never Knew Sunken Fool (FT.Si. Schroeder)-2017

- Territory The Blaze (2017)

- I don't tieed a reason Dizzie Rascal (2014)

- Firstfire Bonobo (2013)

- Rub Peaches (2015) 
Austral Comunicación

Volumen 9, número 2 (Diciembre de 2020): 275-298. ISSN 2313-9129

- Tiny Torture s Flying Lotus (2012)

- My club The Asteroyd Galaxy Tour (2014)

- Oasis La chica (2015)

- Civilization Justice (2011)

- The Lava/Part 1 Equator (2014)

- Source Fever the Ghost (2014)

Se pretende analizar y describir el tipo de videoclip musical en el canal especializado Music Video Land, que cuenta con una calidad expresiva y estética mayor que los videoclips mainstream, los cuales suelen estar más presentes en YouTube.

Se ha optado por una metodología de tipo cuantitativo, analizando criterios que describen la especificidad del videoclip. Para ello, se aplican criterios de análisis clásico de tipo cuantitativo -tratando de medir la popularidad de los clips- y criterios cualitativos clásicos en la descripción de análisis, como son el tipo de videoclip, su tipo de relación imagen/música y de relación imagen/letra, los cuales describen la narratividad/discursividad del videoclip y su interrelación entre las materias sonoras (música y letra) y las técnicas de animación y las especializadas de realización (preferentemente de posproducción) de la banda icónica.

De esta manera, se han observado los siguientes criterios, que serán descritos en los resultados:

- Si es Video StaffPick (o no).

- Cantidad de visualizaciones.

- Cantidad de me gusta.

- Cantidad de comentarios por videoclip.

- Tipo de videoclip: conceptual, performance, narrativo, mixto.

Se describe al videoclip narrativo como "todo videoclip que contenga al menos un programa narrativo, aunque este sea simple, es decir, aunque no esté formado por diversos programas narrativos adjuntos o subordinados" (Sedeño-Valdellós, 2002, p. 65). En cuanto a este, si seguimos a Caro (2014), el narrativo es una tipología bastante minoritaria en el videoclip actual y desde siempre. En cuanto al vídeo conceptual, desarrolla una propuesta visual no narrativa ni ligada al concierto. Se trata de proponer un proceso de visualización del tema musical o concept "un determinado repertorio de personajes, espacios, formas, colores, gestos y movimientos (micronarrativas) con los que se elabora un microuniverso rítmico y visual que caracterizará a la pieza musical y al artista" (Leguizamón, 2001, p. 255). También el videoclip performance supone un imaginario diferente, pues trata de representar o recrear el momento de concierto en directo o actuación en vivo. 
Ana Sedeño-Valdellós

Videoclip musical y creatividad audiovisual: un análisis del canal Music Video Land de Vimeo

Por otro lado, los videoclips mixtos (conceptual/performance o narrativo/performance) han sido los preferidos de la industria de la música y suponen un canon estético de la puesta en escena y de relación con el fan/espectador: estos tipos permiten ampliar los significados del discurso musical del género específico y de las letras con una parte narrativa y/o de mensaje sin renunciar a una presentación física de los artistas, manteniendo así el objetivo publicitario del videoclip, formato audiovisual promocional.

- Tipo de técnica visual especializada. Se detecta la presencia de una técnica creativa audiovisual más allá de la realización clásica por montaje, como efectos especiales, técnicas de composición de imagen, encuadre o fotográficas o de cámara. Consideremos que este tipo de recursos "se ha convertido en trampolín de propuestas visuales hasta ahora nunca vistas gracias a la aplicación de efectos digitales (VFX en la posproducción)" (Jódar-Marín, 2017, p. 26). Las técnicas específicas que se han localizado son plano subjetivo, cortinillas y efectos de encuadre, VFX, cámara lenta, super slow motion, efectos de composición (chroma), plano secuencia, distorsión de lente y efectos fotográficos.

- Localización de videoclips con animación (sí o no).

- Tipo de animación empleada. Según los estilos de animación descritos claramente en 10 estilos de animación, ¿cuál es su favorito? (Renderforest, 2019): animación $2 \mathrm{D}$, animación $3 \mathrm{D}$, animación de pizarra, rotoscopia, animación mecánica, stop motion, animatronics, animación de recorte, animación tipográfica, animación de arcilla, plastilina.

- Relación música/visuales. Se sigue aquí la clasificación clásica de Simeon (1992), que habla de correspondencias o acuerdos entre la materia visual y sonora: la correspondencia kinética, la correspondencia sintagmática y la correspondencia de contenido. La kinética se refiere a la velocidad de la música en relación a la velocidad de la acción. Se produce normalmente en los videoclips performances con presencia de coreografías o fórmulas en las que se visualiza el ritmo o tempo musical por parámetros visuales (cambio de plano, tipo de movimiento de cámara, etc.). La correspondencia sintagmática se refiere al modo en el que la segmentación de la música "secunda" la segmentación del texto. Este tipo tiene que ver con cambios de puesta en escena en momentos de cambios de sección (de estrofa a estribillo y viceversa, de estribillo a puente, etc.). Suele ser común en los videoclips mixtos. La correspondencia de contenido se refiere a alusiones directas en la banda visual respecto a lo sonoro (especialmente las letras). Esta última se relaciona con el criterio de relación música/texto.

Es interesante explicitar que esta categoría de análisis podría ampliarse, aunque ello supondría complejizar una categoría que creemos que describe, en este nivel y de 
forma genérica, cómo el videoclip, como formato audiovisual actual, dispone la relación entre las materias audiovisuales.

- Relación música/texto. Este criterio se refiere al grado en el que la banda visual continúa la canción de acuerdo a la letra. Para ello, se ha realizado un análisis genérico de la banda imagen y se ha tratado de encontrar alguna relación con la letra. La letra de la canción, punto de partida de este criterio, estaba en casi todas las ocasiones en inglés (aunque también en francés y en ruso) y se ha traducido con ayuda de Google Translate. Tras esto, se estuvo en posición de clasificar el vídeo según contuviese una ilustración, ampliación o disyunción. Siguiendo a Goodwin (1992), en la amplificación (la mayoría de los videoclips se encuentran en esta categoría) se añaden acciones visuales que no se encuentran nombradas directamente en la letra, opción literal que significaría una ilustración del vídeo con respecto a la canción. En cuanto a la disyunción, se produce cuando la letra no tiene relación evidente con la imagen o, incluso, ambas se contradicen: "Cuando el autor alude a un significado de la canción que es diferente a lo que se infiere por la imagen del vídeo" (Goodwin, 1992, p. 88).

- Tipo de música. Resulta importante relacionar los tipos de videoclips y las técnicas más empleadas con el tipo de música, diferenciándola entre alternativel indie, dance/electrónica, punk/rock, pop, hip-hop/rap, rhythm and blues/soul, música clásica, house y folk. Si se considera la dificultad de distinguir una canción por su género en la actualidad -debido a la hibridación musical y a las diversas clasificaciones-, en caso de duda se ha optado por consultar cómo aparece tipificada la canción o el autor en su página oficial o en Wikipedia. Este criterio, escasamente tratado en los trabajos actuales sobre videoclip, sí apareció entre los intereses de análisis textuales y de contenido de la década del 80 , como en el caso de Tapper, Thorson y Blac (1994), quienes establecían atribuciones diferentes en cada género musical, aunque su incidencia no se ha abordado categóricamente en los estudios sobre videoclip.

\section{Resultados}

Como primer dato subrayable querríamos destacar la coherencia entre datos cuantitativos de likes, visualizaciones y comentarios en cada caso. Hay que recalcar una correlación de manera clara y generalizada, lo que indica el Coeficiente de Correlación de Pearson de 0,91 entre el número de visualizaciones y el número de likes. Esto obedece a una lógica de retroalimentación, que existe también cuando se analizan los videoclips más visualizados del año en determinados períodos en YouTube. Esta especie de efecto canal podría ser clave en la viralización de determinados videoclips entre los usuarios, aunque quede fuera de los 
Ana Sedeño-Valdellós

Videoclip musical y creatividad audiovisual: un análisis del canal Music Video Land de Vimeo

límites de este estudio. De estos 150 videoclips, solo 12 no son Staff Picks, es decir, el 92\% de ellos han sido curados -elegidos- especialmente por el equipo de IMVdb.

Una de las cuestiones nucleares en la definición del perfil de videoclip del canal se dirime en la tipología. Se cuentan 35 narrativos, 90 conceptuales y 8 performances, mientras que 17 son mixtos (Figura 2). Se confirma entonces esa idea de que la mayoría son conceptuales, lo que supone un dato descriptivo interesante sobre el perfil del canal, lejano a los más visualizados o con más me gusta de YouTube -analizados por Sedeño-Valdellós, Rodríguez-López y Roger-Acuña (2016)-, en el cual la mayoría eran performance. En aquellos, la muestra contaba con los más visualizados y creativos de YouTube en 2013 y 2014, realizando una comparación.

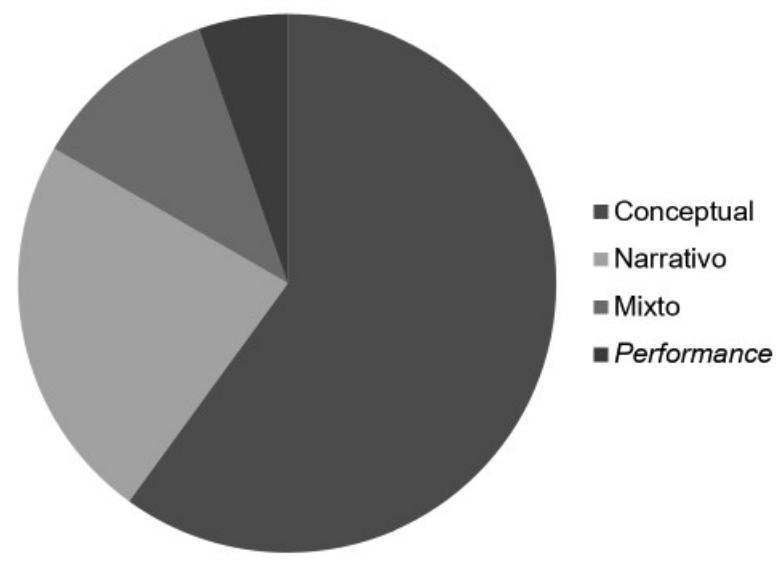

Figura 2. Tipos de videoclips en Music Video Land.

En cuanto a la animación, es interesante apuntar que de los 36 videoclips que la contienen la mayoría es del tipo 2D, con 17 casos, seguidos por los 14 casos de animación 3D. Le siguen la animación de recorte (3 casos), el stop motion ( 2 casos), la animación tipográfica (2 casos) y el animatronics (2). Hay que decir que 25 de los que contienen animación son conceptuales, 9 son narrativos y 2 son mixtos. Como puede comprobarse, la propia categoría de performance parece contraria a la animación, pues no existe ningún caso de vídeo performance con técnicas de animación. Podemos constatar que se utiliza la animación 3D para la banda visual completa del videoclip (como los casos de Splitting the atom de Massive Attack, Civilization de Justice o Ma'agalim de Jane Bordeaux) o la 2D, ya sea empleando toda la banda visual con el tradicional dibujo animado o integrada con imagen secuencial fotográfica, como en Grades de King, en The Less I know the better de Tame Impala o en Tiny Tortures de Flying Lotus (Figura 3). Estas opciones ocupan los primeros puestos en los 50-60 videoclips con más me gusta del canal. Las técnicas minoritarias son stop motion, animación tipográfica y de recorte. 
Austral Cmunicación

Volumen 9, número 2 (Diciembre de 2020): 275-298. ISSN 2313-9129

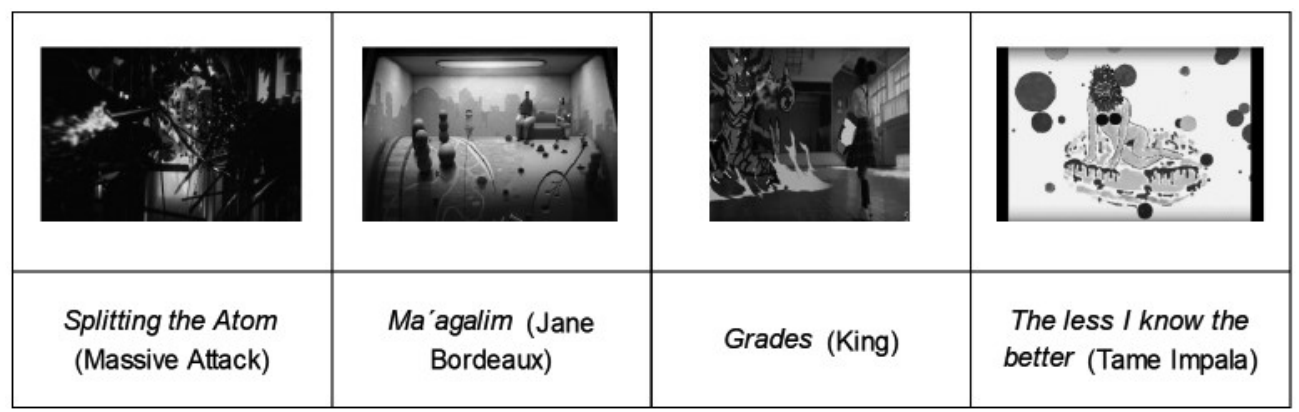

Figura 3. Ejemplos de tipo de animación.

Por otro lado, la complejidad creativa de la posproducción audiovisual contemporánea tiene como consecuencia la problemática de la distinción entre las técnicas de animación y las de VFX: videoclips como Magma de The Vein combinan ambas técnicas y su incrustación a través de plugins, los cuales ofrecen esos flujos de pintura en movimiento sobre una banda icónica grabada con técnicas digitales (Figura 4).

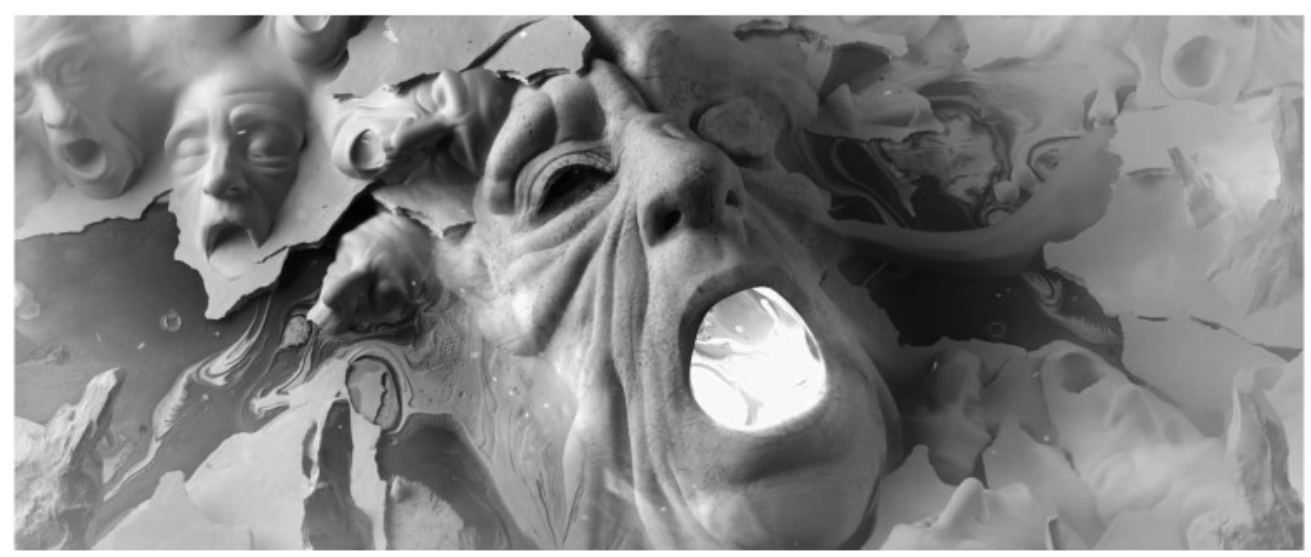

Figura 4. Magma (The Vein, 2012).

Este caso es complementario o contrario a las técnicas de Grades (King) o Tiny Tortures (Flying Lotus), en los que la imagen real y la imagen animada, compartiendo encuadre, explicitan claramente sus diferencias visuales.

El tipo de música resulta una interesante forma de analizar el canal, así como a sus usuarios. La música dance/electrónica es la más representada en el canal con 62 vídeos, seguida de la alternative/indie con 45. Tras ellas, se encuentran el hip-hop/rap (14), la música pop (11) y el punk/rock (9), que suponen un segundo grupo de tendencia en este caso. Los géneros menos representados son el rhythm and blues (4), el house (2), la música clásica (1) y el folk (1) (Figura 5). 


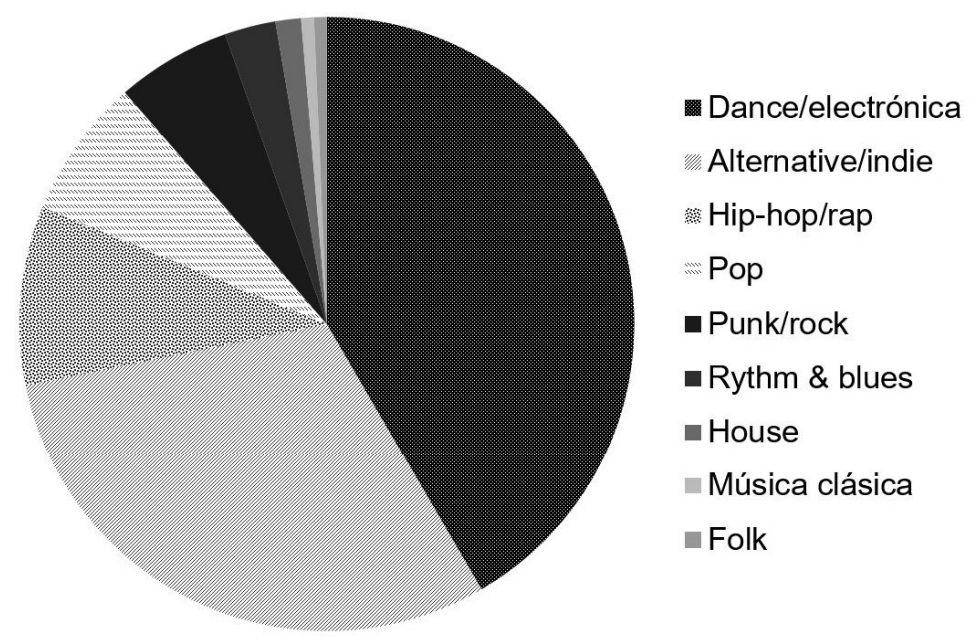

Figura 5. Tipos de géneros musicales.

Una relación destacable y descriptiva del perfil de este videoclip de autor supone la interrelación entre tipo de videoclip y género musical.

De esta manera, de los 150 videos, son narrativos 13 de los de dance/electrónica y 12 de los alternative/indie. Si examinamos los mismos tipos con la tipología de conceptual, 41 son de dance electrónica y 22 de alternative/indie. Por otro lado, si se observa la Tabla 1, puede comprobarse cómo estos se concentran en los primeros 50 puestos. Por ello, podríamos decir que los videoclips conceptuales de dance/electrónica o de música independiente resultan los preferidos del comisario (y del espectador, atendiendo a que estos acumulan el mayor número de me gusta) de Music Video Land, un dato que describe el alejamiento del canal de la música mainstream que protagonizan las listas de mayor visualización y me gusta de YouTube. El gusto por un videoclip alternativo, alejado del performance de la música pop nos permite perfilar mucho este tipo de videoclip. Asimismo, siguiendo con este análisis, 7 de los conceptuales son punk/rock, 9 son pop, 5 son hip-hop/rap y 2 son house. Con respecto a la parte narrativa, las músicas menos representadas son el hip-hop/rap (3), el punk/rock (2 casos), el pop ( 2 casos), el rhythm and blues (1 caso) y la música clásica (1 caso). Los performance son alternativel indie (4 casos), dance/electrónica (2 casos) y hip-hop/rap (1 caso).

Es interesante incluir un análisis del tipo de videoclip según su relación con el tipo de sincronía o relación música/imagen, pues permite conocer si algunos tipos de fórmulas de representación son proclives a lo kinético o a lo sintagmático. En este sentido, podríamos apuntar que 22 de los videoclips narrativos son kinéticos y 8 son sintagmáticos, mientras que 72 de los conceptuales son kinéticos y 7 son sintagmáticos. Esta proporción permite discutir cómo los videos conceptuales tienen tendencia 
hacia lo kinético en la sincronía, lo que tiene sentido pues su no narratividad y falta de periodos o fases de una representación visual no permiten un montaje adaptado a la estructura musical, condición que necesita lo sintagmático. En este sentido, parecen diferenciarse directamente de lo que ocurre con los videoclips analizados de YouTube, en el que la mayoría era performance con tendencia a lo sintagmático. En este criterio de tendencia hacia lo kinético nos gustaría destacar una inclinación hacia la visualización de texturas musicales y pulsos, que nos remite a lo dicho por Vernallis (2013): véanse videoclips como Katachi de Shugo Tokumaru, Magma de The Vein o No reason de Bonobo para experimentar diferentes fórmulas de realización en las que se visualizan estos materiales musicales, ya sea desde el pulso musical o desde la continuidad del flujo musical.

Por ejemplo, No reason de Bonobo o Pursuit de Gesaffelstein emplean el travelling hacia adelante y atrás, respectivamente, como manera de visualización de la continuidad propia de la repetición de texturas y notas percusivas de la música electrónica. En este caso, el cambio visual se contiene en el flujo mantenido por el plano secuencia.

En cuanto a las técnicas visuales especiales de posproducción que se pueden observar en 101 de los 150 vídeos, hay que destacar la cámara lenta con 44 casos, muy por encima de las demás. En este caso, se ha contabilizado cuando ocurre en más de una escena para así poder detectar un uso generalizado, pues la cámara lenta es un recurso tradicional del videoclip desde sus comienzos, como lo han señalado Leguizamón (2001) y Vernallis (2004). Hay que destacar el super slow motion de la canción Unconditional rebel, una categoría distinta por lo significativo de la técnica con cámara Phantom $4 \mathrm{k}$ a 1/100 cuadros por segundo y solo 5 segundos de metraje.

Un recurso más sorpresivo es la elección de los efectos de composición o chroma: con 39 casos, suponen una posibilidad variadísima de posproducción y juego de capas de la imagen con todo tipo de soluciones visuales. Se puede comprobar cómo, ya sea a través del layering, con efectos de máscara o la incrustación de unas imágenes en otras, produce todo tipo de efectos de extrañamiento y creación de imágenes de gran resultado efectista y estético: en $U p$ \& Up (Coldplay), diversos paisajes se engarzan con acciones en una menor dimensión; en The Hundred in the Hands (Pigeons), la protagonista flota o escupe fuego; en Moments (Teebs), las cortinillas por modificación del canal alfa de la imagen hacen que no haya montaje en el sentido de cambio de plano tradicional; en Wide Open (The Chemical Brothers), el chroma lineal con efecto 3D ocasiona la desaparición del cuerpo de la bailarina (Figura 6). 


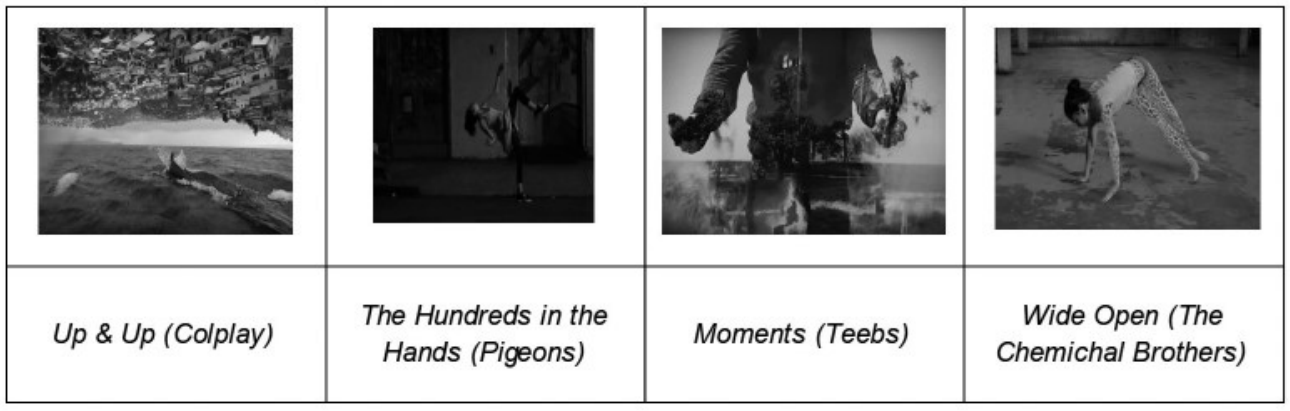

Figura 6. Diferentes ejemplos de efectos de composición (chroma).

Con respecto a las otras opciones, 5 son planos secuencia y 12 tienen efectos especiales (VFX). Tres vídeos cuentan con distorsiones de lente y efectos fotográficos, 2 tienen efectos de encuadre y cortinillas y 2 transmiten su discurso a través de planos subjetivos (los dos primeros videoclips de la lista). Se comprueba un gusto por técnicas de posproducción y del discurso que remapean el curso temporal de la imagen lineal y una composición por capas repleta de efectos (Figura 7).

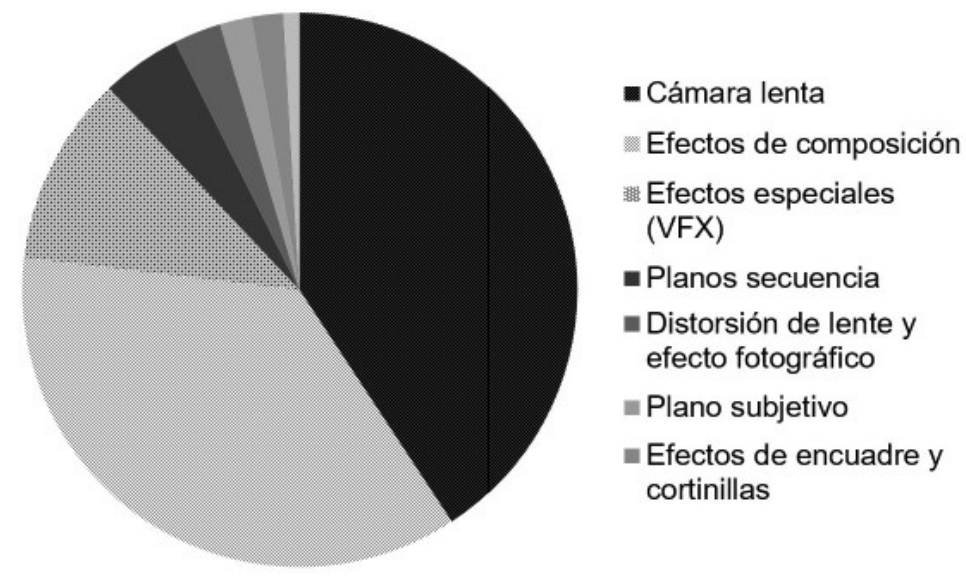

Figura 7. Tipo de técnica visual especializada.

Puesto que estas técnicas no son excluyentes, 13 de estos 101 videoclips las combinan, como los 6 que tienen cámara lenta y efectos de composición y chroma. Ello confirma la extrema maleabilidad de la imagen electrónica digital que eligen los videoclips del canal.

En relación con la sincronía músicovisual, contamos con 131 casos de correspondencia kinética, que suele provenir de correspondencia rítmica, o con el pulso de la canción: fórmulas que aparecen como muy adecuadas para la visualización de la tex- 
tura de la música dance/electrónica y de la indie. Junto a ellas, lo sintagmático puede contarse hasta en 35 casos, la mayoría de ellos compartidos con correspondencias kinéticas. Como conclusión de esta variable, podemos apuntar que en el tipo de visualización de la materia musical escogida en los videoclips priman elementos rítmicos o estructurales de las canciones más que los de contenido (letra), lo que es coherente con el gusto por los componentes de posproducción y de edición y con la propia naturaleza del formato.

En cuanto a la relación imagen/texto, hay que comentar 5 casos de ilustración, 69 de ampliación y 58 de disyunción (Figura 8). Hay 17 de música instrumental, es decir que los videoclips realizan una propuesta visual que no discurre en un seguimiento generalizado del contenido propositivo de la letra, sino que aportan un suplemento de creatividad.

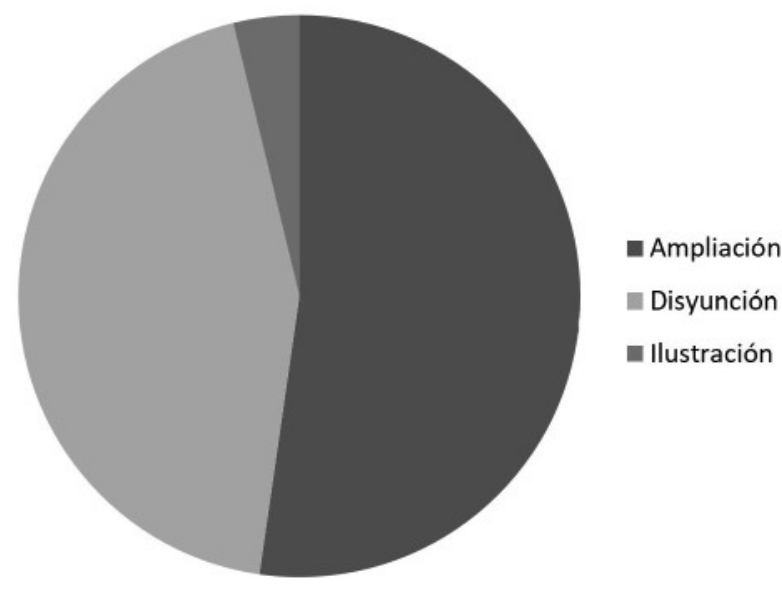

Figura 8. Relación texto (letra)/imagen.

\section{Conclusiones}

El videoclip musical contemporáneo se caracteriza por su variedad y riqueza en la tipología de propuestas. Además de formato periférico dentro del universo audiovisual, supone el de mayor experimentación, no solo en la actualidad (su recorrido histórico así lo demuestra). La gran cantidad de técnicas y posibilidades de hibridación visual y modificación de parámetros temporales y espaciales que permite la tecnología de edición digital han sido probadas desde su descubrimiento por la industria de la producción audiovisual

El tipo de videoclip que se encuentra en el canal Music Video Land tiende a la no narratividad y a la huida de la simple performance como puesta en escena para plantear 
Ana Sedeño-Valdellós

Videoclip musical y creatividad audiovisual: un análisis del canal Music Video Land de Vimeo

su discurso visual. Lo conceptual domina en estos videoclips y en ellos se despliega un ambiente o estética de tipo abstracto, una secuencia de imágenes con un concepto común. Esta temporalidad descriptiva de acciones que supone lo conceptual resulta una propuesta visual que amplifica o se separa del significado de la letra, pero siempre la toma como referencia.

Esta huida de la narratividad tiene también un desinterés por lo mimético, en lo espacial y en lo temporal del transcurrir naturalizado de lo perceptivo: de ahí que puedan encontrarse tantas técnicas visuales de posproducción, como cámara lenta y otras modificaciones del tiempo lineal, que suponen un gusto por el time remapping (cámara lenta, modificaciones temporales, efectos de composición que desnaturalizan esta representación clásica de imagen y sonido) y plantean una reconfiguración de la representación lineal del tiempo. Con ello, este tipo de vídeos componen una estructura de recursos de no narratividad, representación conceptual y técnicas de modificación espaciotemporal, una especie de sistema de avanzada creatividad visual que utiliza todas las técnicas digitales de posproducción y prioriza la relación kinética músicovisual.

\section{Referencias}

Arroyo Almaraz, I. y Baños González, M. (2013). La eficacia de la comunicación de las organizaciones del Tercer Sector en los vídeos emitidos a través de YouTube. Historia y Comunicación Social, (18), 615-626. http://dx.doi.org/10.5209/rev_ HICS.2013.v18.43993.

Austerlitz, S. (2007). Money For Nothing: A History of the Music Video from the Beatles to the White Stripes. Nueva York: Continuum Books.

Berland, J. (2008). Postmusics. En Bloustein, G., Luckman, S. y Petrs, M. (Eds.), Sonic synergies: music, technology, community, Identity. Aldershot: Ashgate.

Caro, A. M. (2014). Elementos narrativos en el videoclip: desde el nacimiento de la MTV a la era YouTube (1981-2011). [Tesis doctoral]. Departamento de Comunicación Audiovisual y Publicidad y Literatura, Universidad de Sevilla.

Goodwin, A. (1992). Dancing in the distraction factory: Music television and popular culture. Minneapolis: University of Minnesota Press.

Jódar-Marín, J. A. (2017). Evolución del montaje y postproducción del videoclip musical: del jumpcut a los VFX como paradigma de iconicidad y puesta en escena. Revista Mediterránea de Comunicación, 8(2), 119-128. https://www.doi. org/10.14198/MEDCOM2017.8.2.8.

Karpovich, A. (2009). The Audiences as editor: The role of Beta Readers in Online fan Fiction Communities. En Helleksen, K. y Busse, K. (Eds.), Fan Fiction and Fan Communities in the Age of the Internet: new Essays. Jefferson: McFarland.

Kong, Q., Rizoiu, M.A., Wu, S. y Xie, L. (2018). Will This Video Go Viral? Explaining and 
Austral Comunicación

Volumen 9, número 2 (Diciembre de 2020): 275-298. ISSN 2313-9129

Predicting the Popularity of Youtube Videos. WWW'18: Companion Proceedings of the The Web Conference 2018, 175-178. https://doi.org/10.1145/3184558.3186972.

Korsgaard, M. (2012). Creation and Erasure: Music Video as a Signaletic Form of Practice. Journal of Aesthetics \& Culture, 4. https://doi.org/10.3402/jac.v4i0.18151.

Korsgaard, M. (2013). Music Video Transformed. En Vernallis, C., Herzog, A. y Richardson, J. (Eds.), The Oxford Handbook of Sound and Image. Nueva York: Oxford University Press.

Korsgaard, M. B. (2018). Music video after MTV. Audiovisual studies, New media, and Popular Music. Nueva York: Routledge.

Leguizamón, J. A. (2001). El videoclip como formato o género $h$. Obtenido el 20 de febrero de 2020 de http://www.archivo-semiotica.com.ar/Leguiz.html.

Manovich, L. (2013). Software takes command. Nueva York: Bloomsbury Academic.

Peverini, P. (2010). The Aesthetics of Music Videos: An Open Debate. En Keazor, H. y Wübbena, T. (Eds.), Rewind, Play, Fast Forward. The Past, Present and Future of the Music Video (pp. 135-153). Bielefeld: transcript.

Picazo-Sánchez, L. (2016). Patrones del comportamiento viral en vídeo. Modelos de contagio viral en YouTube. Documentación de las Ciencias de la Información, (39), 313-331. http://dx.doi.org/10.5209/DCIN.54421.

Renderforest (2019). 10 estilos de animación, ¿cuál es su favorito? Obtenido el 5 de febrero de 2020 de https://www.renderforest.com/es/blog/10-animation-styles.

Sachak-Patwa, R., Fadai, N. T., Van Gorder, R. A. (2018). Understanding viral videodynamics through and epidemic modelling approach. Physica A: Statiscical Mecanics and its Applications, (502), 416-435. https://doi.org/10.1016/j. physa.2018.02.083.

Scolari, C. (2013). Narrativas Transmedia: Cuando todos los medios cuentan. Barcelona: Deusto.

Sedeño-Valdellós, A. (2002). Lenguaje del videoclip. Málaga: Servicio de Publicaciones de la Universidad de Málaga.

Sedeño-Valdellós, A. (2012). Producción social de videoclips. Fenómeno fandom y vídeo musical en crisis. Revista Comunicación, 1(10), 1224-1235. Obtenido el 10 de enero de 2020 de http://www.revistacomunicacion.org/pdf/n10/mesa7/095. Produccion_social_de_videoclips-Fenomeno_fandom_y_video_musical_en_ crisis.pdf.

Sedeño-Valdellós, A., Rodríguez-López, J. y Roger-Acuña, S. (2016). El videoclip postelevisivo actual. Propuesta metodológica y análisis. Revista Latina de Comunicación Social, (71), 332-348. Obtenido el 15 de diciembre de 2020 de http:// www.revistalatinacs.org/071/paper/1098/18es.html.

Shaviro, S. (2010). Post-cinematic affect. Wincheester and Whasghinton: Zero Books. 
Videoclip musical y creatividad audiovisual: un análisis del canal Music Video Land de Vimeo

Simeon, E. (1992). Programmi narrative e stratificazioni del senso nella musica per film. Il caso di "Entr'acte". En Dalmonte, R. y Baroni, M. (Eds.), Atti di Secondo Convegno Europeo di Analisi Musicale (pp. 389-399). Trento: Università degli Studi di Trento.

Tapper, J., Thorson, E. y Blac, D. (1994). Profile: Variations in music videos as a function of their musical genre. Journal of Broadcasting and Electronic Media, 38(1), 103113. https://doi.org/10.1080/08838159409364249.

Vernallis, C. (2004). Experiencing music video. Nueva York: Columbia University Press. Vernallis, C. (2013). Unruly Media: YouTube, Music Video, and the New Digital Cinema. Oxford: Oxford University Press. 